\title{
Self-Concept in Children with Down Syndrome
}

\author{
Sayoni Saha ${ }^{1}$, Eric Doran ${ }^{1}$, Kathryn E. Osann ${ }^{3}$, Christy Hom $^{1,4}$, Nina Movsesyan ${ }^{1}$, Diana D. \\ Rosa $^{1}$, Anne Tournay ${ }^{1}$, and Ira T. Lott ${ }^{1,2}$ \\ ${ }^{1}$ Department of Pediatrics, School of Medicine, University of California, Irvine (UCI), Irvine, \\ California \\ 2 Department of Neurology, School of Medicine, University of California, Irvine (UCI), Irvine, \\ California \\ ${ }^{3}$ Department of Medicine, School of Medicine, University of California, Irvine (UCI), Irvine, \\ California \\ ${ }^{4}$ Department of Psychiatry, School of Medicine, University of California, Irvine (UCI), Irvine, \\ California
}

\begin{abstract}
Self-concept is a critical indicator of quality of life but few studies have examined this subject in children with Down syndrome (DS). In this study, we propose a novel methodology to assess the self-concept of children with DS by analyzing their responses towards two dolls, one with a "typically developing" (TD) appearance and one with the phenotypic features of DS. Fifty-four children with DS participated in play sessions with both dolls and were then interviewed to assess doll preference, resemblance, and attribution of positive qualities. We observed that children with DS: 1) exhibited a preference for the TD doll regardless of age, gender, IQ or self-awareness; 2) attributed more positive qualities to the TD doll than the DS doll; and 3) believed that they resembled the TD doll, rather than the more phenotypically accurate representation of themselves. Older participants were more likely to exhibit self-recognition by this technique. These findings contribute to current understandings of how people with DS view themselves and their disability.
\end{abstract}

\section{Keywords}

Down syndrome; Self-concept; Doll test; Quality of life

\section{INTRODUCTION}

Self-concept may be defined as how one thinks and feels about oneself [Glenn and Cunningham, 2001] and is a core indicator of quality of life [Schalock, 2004; Ziller, 1974]. There is a strong relationship between self-concept, physical health, and psychological wellbeing [Campbell et al., 1996; Campbell et al., 2003; Rafaeli-Mor and Steinberg, 2002].

Corresponding Author: Ira T. Lott Department of Pediatrics, UC Irvine Medical Center, 101 The City Drive, ZC 4482, Orange CA 92868, Phone: (714) 456-5333, Fax: (714) 456-8466, itlott@uci.edu.

Ms. Saha completed this work as a student research intern from Whitney High School, Cerritos, CA, and presented this data as an Intel Science Talent Search 2012 finalist, Washington, DC, March 8-13, 2012. 
Self-concept in individuals with developmental intellectual disabilities (DID) is impacted significantly by societal stigma [Jahoda and Markova, 2004]. In a comprehensive review of stigma in persons with DID, Ali et al. [2012] found that internalization of stigma can lead to negative self-esteem [Abraham et al., 2002; Paterson et al., 2012; Petrovski and Gleeson, 1997; Szivos-Bach, 1993], negative self-evaluations [Dagnan and Waring, 2004] and psychiatric symptoms [Paterson et al., 2012]. The negative effects of internalized stigma may impair psychological well-being at many levels. Jones [2012] explored self-concept in adolescents with DID and found that those that self-identified as having a disability described themselves in negative terms. Overall, there was a lack of constructive and affirmative language used when participants described their disability. These studies point to the need for objective studies of self-concept to further understand possible internalized stigmas in vulnerable populations such as individuals with DID.

Measures of self-concept in individuals with DID have included open-ended questions and surveys [Begley and Lewis, 1998]. However, open-ended questions may be difficult for individuals with linguistic and cognitive delays to answer. Additional issues that might confound study results include limited attention span as well as external influences from parents, caregivers, and the examiner. For example, there may be an unequal distribution of influence between examiner and subject, which can induce bias in testing results [Begley and Lewis, 1998]. Thus, a new approach is needed in which self-concept may be measured and confounding issues minimized.

Down syndrome (DS) is one of the most common known genetic causes of DID worldwide. In the United States the estimated population prevalence of DS is 8.27 per 10,000 persons [Presson et al., 2013] and the estimated birth prevalence is 14.47 per 10,000 live births [Parker et al., 2010]. However, very little is known about self-concept in this population.

In a study of self-awareness among 77 children with DS using interviews, standardized tests, and photographs, over half were considered to have some level of self-awareness about their diagnosis but $13 \%$ refused to talk about their condition during their interviews [Cunningham and Glenn, 2004]. The authors identified one particular difficulty in determining selfconcept in this population - only children with DS who had a mental age of 8 years or more were capable of making relative social comparisons and forming complex social categories of their disability [Cunningham and Glenn, 2004]. Therefore, mental age may affect individuals with DS ability to form a self-concept and affect the assessment of their selfconcept due to limited language skills or mental ability. Techniques of assessing self-concept in this population have included interviews, photographs, mailed surveys, and standardized tests [Begley, 1999; Cuskelly and de Jong, 1996; Glenn and Cunningham, 2001]. Begley [1999] identified that individuals with DS did hold views of themselves, which were generally positive. Skotko et al. [2011] used a comprehensive survey format to evaluate selfperception in 266 individuals with DS between ages 12-40 years and found that 96-99\% were happy with their lives, how they looked, and who they were. Those authors identified several limitations to their study including the lack of direct observation and the exclusion of non-verbal or extremely low functioning individuals with DS who would not be able to complete the mailed survey. 
Building upon the previous research and in an attempt to resolve some of the limitations listed above, we sought to ascertain self-concept in children with DS utilizing a more objective measure, in this case a doll test. A doll test is an experimental method by which attitudes of the participants may be determined. The doll test paradigm has been used since the 1940s to study attitudes and stigma. In a classic study, Clark and Clark [1950] investigated self-concept and internalized stigma in African-American school children by examining different attitudes to a dark and a fair-skinned doll. Doll studies have been used to study race and sexual identity [Jacobs, 1992; Wohlwend, 2012]. In the human development literature, a common use of doll studies has been to look at childhood development and in particular how aggression and social anxiety manifest in play habits [Levin and Sears, 1956; Pass et al., 2012; Sears, 1951; Sears et al., 1946]. Such methodology has also been used to examine symbolic play in adolescents with autism but not in DS [Marcu et al., 2009; Thiemann-Bourque et al., 2012].

We do not know how variables of self-concept may be expressed in children with DS and the current study is an attempt to use doll play to systematically explore this issue.

\section{METHODS}

\section{Participants}

Children with DS between ages 4 and 17 years were recruited with the assistance of the Down Syndrome Association of Orange County and the Down Syndrome Association of Los Angeles. Children were enrolled who lived in households where English was the primary language, and had no prior exposure to the dolls utilized in this study. A mandated study requirement was that the participants be capable of attention to the experimental tasks, regardless of their history of medical co-morbidities. The University of California, Irvine Institutional Review Board approved the study including the procedures for informed consent. Verbal assent was obtained from the participating child following a discussion of study procedures appropriate to the child's level of understanding.

\section{Instruments}

As seen below, a demographic questionnaire was administered to the parents of the participating child to address age, gender, ethnicity, contact with other individuals with DS, and their opinion as to the child's self-awareness of the diagnosis. Parent-reported child's self-awareness was considered to be a dichotomous variable, defined as to whether or not the parent believed the child was aware of their diagnosis of DS. The frequency of subject contact with other children who had DS was recorded as weekly, monthly or more. Trained personnel administered three psychological tests:

1) The Kaufman Brief Intelligence Test, Second Edition (KBIT-2) [Kaufman and Kaufman, 2004] was used to provide a composite IQ score as well as Verbal and Nonverbal Scale scores. IQ was defined by the composite KBIT-2 score and agebased standard scores were used.

2) The Vineland Adaptive Behavior Scales, Second Edition - Parent/Caregiver Rating form (Vineland-II) [Sparrow et al., 2005] was used to assess the 
developmental skills of each participant. Both of these scales are designed for use with developmentally disabled populations. The Adaptive Behavior Composite, a summary of the individual's abilities across 3-4 domains (Communication, Daily Living Skills, Socialization and Motor Skills) was used.

3) Self-recognition was measured by the mirror self-recognition task [Gallup, 1970]. The mirror self-recognition test involves asking participants to look at a provided mirror. If the participant verbally identifies or points to themselves in response to the question "Who's that in the mirror?" participants have passed the test.

\section{Dolls}

The dolls used in the study were manufactured by Helga's European Specialty Toys (HEST) and are marketed to families, organizations, and medical providers to foster a better understanding of DS. The doll representing the appearance of a typical child in the general population (TD) and the DS doll are seen in Figure 1. Phenotypic features of the DS doll included slanted almond shaped eyes to represent the sloping eye shape with epicanthic skin folds, mid-face hypoplasia, Brushfield spots, small ears slightly folded at the top, shortened fingers, separation between the first toe and second toe, flattened nasal bridge, and a flattened occiput (Figs 1 and 2a, b, c). The clothing, skin color, hair color and hairstyles were identical between the TD and DS dolls. Gender distinction between dolls was based upon clothing and hairstyle (Fig 1). Male participants were given male dolls and female participants were given female dolls.

\section{Free-play session}

A 3 minute initial free-play session with both dolls was conducted to capture the child's spontaneous play habits with minimal direction by the observer. The session allowed the child to become comfortable with the environment and to establish rapport with the examiner before transitioning to a scripted-play session. The child was asked to sit at the center of a 17 by 42 inch table equidistant from the two dolls that were separated by 7 to 8 inches. Other toys used to encourage spontaneous play comprised a cell phone, dinosaur, children's books, cars, truck, hairbrush, baby bottle, bowls, and a spoon. These toys were placed on the table between the two dolls. The free-play session was video recorded and coded for total length of time as well as length of play time with each doll.

\section{Scripted-play session}

Following the free-play session, the examiner suggested that it was the participant's "make believe" birthday and that there would be a "party" with both dolls invited as guests. All objects were cleared from the table and the dolls were placed in chairs at the table's edge opposite from the child. In order to give structure to the doll exposure, we utilized a standardized script that required children to perform birthday party tasks such as blowing out candles, feeding the dolls cake and juice, cleaning the dolls, and putting them down for a nap. 
The participating parent was in the same room as the child during the play sessions but was seated behind the child and slightly to one side. The parent was instructed to sit quietly, act disinterested, and to complete the Vineland-II. If the child sought the parent's attention, the parent was asked to read back one of the provided statements to redirect the child's attention to the researcher and play session. The purpose of the limited parental interaction was to minimize the parent's and examiner's influence over the child's play. The researcher did not prompt the child to play with a specific doll, did not react to comments about either doll, and did not engage the child in extensive conversation.

\section{Participant interview}

At the completion of the scripted-play session, the table was cleared and the dolls were placed standing against a white background directly in front of the child. With their attention directed at the dolls, participants were asked to choose which doll had each of the 5 specified attributes, identified in Table I. Questions were asked regarding intelligence, social, personality, physical appearance, and physical skill. The participant was also asked which doll they preferred, and which doll resembled them more. At the end of each question, the child was asked to explain their answer and their answers were entered as data for possible future analysis. This interview session and the preceding play sessions were video recorded for data capture and verification.

\section{Statistical Methods}

This was a pilot study designed to describe doll preference in a sample of children with DS and the characteristics associated with doll preference. Comparisons of subgroups were conducted for the purpose of generating hypotheses for further testing in larger, adequately powered studies. Doll preference and attribution of positive qualities to the dolls were characterized by descriptive statistics and $95 \%$ Clopper-Pearson confidence intervals. Preference and attribution of positive qualities were compared by gender, parent reported self-awareness, chronological age, and IQ using Fisher's exact test. A summary measure of overall attribution of positive qualities was created to identify the doll most often given positive attributes by the child (at least $60 \%$ of the time or $\geq 3$ of 5 questions). Given the presence of a parent and an examiner in the room, we thought the participant would be more likely to name a positive rather than negative attribute. We defined a positive attribute as the doll choice selected for at least $60 \%$ of the time ( $>3$ of 5 questions). Participants were stratified into two groups by age and IQ at the means. Participants who did not respond to any questions or picked both dolls were excluded from the individual analysis.

Time spent with each doll in the free-play session was captured from the digital video recordings of the sessions and reported as a ratio; time spent interacting with dolls only divided by total time for the entire free-play session (including all toys). Data are described with appropriate descriptive statistics (median and range or mean and SD). The percentage of free-play time spent with each doll was compared using Mann-Whitney nonparametric tests. 


\section{RESULTS}

\section{Participants}

Table II shows demographic characteristics of the participants. Fifty-four children with DS (26 male and 28 female) were enrolled and completed the study. The mean age was 10.1 years ( $\mathrm{SD}=3.7$, range 4.0 to 17.9). The mean KBIT-2 IQ score was $51.6(\mathrm{SD}=10.4)$ and the mean Vineland-II Adaptive Behavior Composite score was 71.5 (SD=7.3). Seventy percent of the parents $(\mathrm{N}=38)$ stated that their child had no awareness of his/her diagnosis of DS.

\section{Preferences and positive attributions}

The majority of participants (71\%) preferred and attributed positive qualities (83\%) to the TD doll (Table III), a finding which was significantly higher than 50\%, the null hypothesis of equal or random preference. The majority of participants also selected the TD doll as having more friends $(72 \%, 95 \%$ CI $58 \%-83 \%)$, a good person $(69 \%, 95 \%$ CI $55 \%-81 \%)$, better at sports $(71 \%, 95 \%$ CI $57 \%-83 \%)$ and the smartest (52\%, 95\% CI 38\%-66\%). There were no significant differences in doll preference by gender, parent-reported self-awareness of DS, age or IQ. There were also no differences in the attribution of positive qualities by the above parameters (Table III). Analysis of the free-play session digital video recordings by an independent examiner confirmed preference for the TD doll by the study participants.

Overall, participants spent a greater proportion of the free-play session with the TD doll than with the DS doll (median 19\% of total play time for TD vs. $4 \%$ for DS; test statistic $=307.5$, $\mathrm{p}=0.01$ ). Similar results were obtained when only the time spent interacting with the dolls was compared between the TD doll (64\%) and the DS doll (36\%). When only time spent interacting with the dolls was compared, participants spend a greater proportion of doll play with the TD doll (median $64 \%$ for TD vs. $36 \%$ for DS; $\mathrm{p}=0.02$ ).

\section{Resemblance and Self-Recognition}

Sixty-nine percent (36/52) observed that the two dolls were different and eighty-eight percent $(46 / 52)$ were able to recognize themselves on the mirror recognition task. Thirty of 52 participants $(58 \%, 95 \%$ CI $43 \%-71 \%)$ chose the TD doll as the doll that most looked like them (Table IV).

Participants who preferred and/or attributed positive attributes to the TD doll were more likely to report they looked like the TD doll while those who preferred and attributed positive qualities to the DS doll were more likely to report resembling this doll. Differences did not reach significance for preference $(\mathrm{p}=0.20)$ but were significant for overall positive attribution ( $\mathrm{p}=0.003$ ). No significant differences in doll resemblance were noted between those who did and did not see the dolls as different and those with and without selfrecognition (Table IV). Participants were more likely to attribute positive qualities to the TD doll regardless of their doll preference, however this likelihood to attribute positive qualities to the TD doll was significantly higher for those who preferred the TD over the DS doll $(\mathrm{p}=0.003)$.

Older participants (age >10 years) were more likely to recognize themselves in the mirror than younger ones $t(50)=-2.548, \mathrm{p}=0.003$. The mean chronological age for participants 
who distinguished that the dolls were different was also older than the participants who reported no difference, $t(50)=-1.963, \mathrm{p}=0.048$.

\section{DISCUSSION}

In this study, we found that children with DS have a clear preference for the TD doll over the DS doll, regardless of age, gender, IQ, or self-awareness. The children tended to attribute more positive qualities to the TD doll than to the DS doll, which suggests that children may view typically developing individuals as being more attractive, smarter, nicer, and more athletic than individuals with the phenotypic features of DS. Children with DS also believed they resembled the TD doll rather than the phenotypically accurate representation of themselves. Lastly, older participants were more likely to exhibit self-recognition.

Our study approached self-concept through direct testing in a controlled setting. Our results do not speak to whether children with DS are happy or unhappy with how they look or whether they are happy with their lives. Rather our study looks at what perceptions children with DS have towards DS based on phenotypic appearance.

Self-concept may be based, in part, on social exposure and "norms" that are present in society [Forehand and Deshpandé, 2001]. Our observations that children with DS prefer the TD doll may be consistent with a trend in the general population in which individuals exhibit a preference for the societal "ideal". A societal ideal typically refers to the body image that is most desired and accepted in a society [Thompson and Stice, 2001]. For example, there is a reported relationship between not looking like the societal ideal and poor self-esteem [Buckley et al., 2006; Michalko, 2009; Monteath and McCabe, 1997; Strahan et al., 2006]. In the general population, Michalko [2009] identified a cultural imperative to make disability disappear into the normative order. Through their interactions with typically developing children [Buckley et al., 2006], children with DS may have been exposed to societal concepts of what is beautiful, smart, or socially acceptable, which may in turn influence their self-concept.

Clark and Clark [1950] found that typically developing African-American children demonstrated a preference for the fair skinned doll and also identified themselves with a skin color markedly lighter than their own. Clark concluded that a possible explanation for his findings was that black children developed an internalized stigma towards the black community and therefore chose to associate with what was perceived as the societal ideal of the time. Such perceived resemblances may occur since it has been reported that younger children show a tendency to minimize their differences from other children perhaps related to a self-concept occurring in the course of early development [Dunlosky and Bjork, 2008]. Consistent with this tendency, the majority of the participants in our study believed that they resembled the same doll to which they attributed the most positive qualities raising the question "Do children with DS have an accurate perception of their physical appearance?". In other words, did they construct their self-concept based upon a perceived view of themselves or an idealized view of themselves? Do they notice the physical differences but choose to ignore them? According to Markus and Kitayama [1991], the early construction of self is critical to childhood development as it may have implications for cognition, emotion, 
and motivation. Therefore, if children with DS do not perceive the differences between themselves and typically developing children, they may go on to develop a positive selfconcept, which may serve as a protective factor against low self-esteem or depression. Or, if children with DS are aware of the differences but choose to ignore them, they may go on to develop an inflated self-concept, which may be beneficial or detrimental.

When typically developing children reach an age of 8 to 10, they are able to compare themselves to others and to self-affiliate [Newman and Ruble, 1988; Stipek et al., 1992]. In our study, older children with DS were significantly more likely to recognize themselves in the mirror and distinguish the physical differences between the two types of dolls, suggesting that self-concept arises at a later stage of development in DS. A child's ability to recognize him or herself in the mirror and to distinguish between the two types of dolls may indicate he or she is beginning to see differences in societal personas. This ability to differentiate between the typical versus the non-typical image suggests that children with DS possess some of the basic components of self, which has been previously identified [Glenn and Cunningham, 2001; Skotko et al., 2011].

This current study builds on some of these previous findings on self that utilized survey and interview methodology among children with DS [Begley and Lewis, 1998; Glenn and Cunningham, 2001; Skotko et al., 2011]. However, young children or individuals with limited cognitive abilities may not be able to effectively communicate their beliefs and views. Thus, this study adds to the field of self-concept measurement by demonstrating the effective use of an alternative methodology - doll play. This approach may obviate some of the limitations of previous studies identified by those authors. Our study also minimized the potential confounding of parental influence by having parents use a standardized script during the study sessions. Children with poor communication skills could also participate.

The advantages of doll play techniques include an ability to work with a variable study population, to gauge opinions of the participants in a short period of time, and to adapt the methodology addressing a wide range of topics [Ammons and Ammons, 1949]. These features of adaptability and flexibility have enabled researchers to use doll play techniques in a variety of populations including those with developmental delay and severe communication impairments [Thiemann-Bourque et al., 2012] wherein over 30 studies were conducted from 1939 to 1977 [Gray-Little and Hafdahl, 2000]. However, this methodology has its limitations. These limitations have included potential difficulty in accurate classification by the participants and the appropriateness of including certain toys and dolls [Byrd, 2012; Phillips, 1945]. Nonetheless, based upon the controlled paradigm in this study, we feel that such doll study limitations have been minimized and that we were able to capture children with DS attitudes and perceptions that may not have been able to otherwise be measured.

Do our findings suggest that children with DS are beginning to internalize stigma about the condition? The topic of self-stigma in people with DID and their caregivers has been reviewed through an extensive meta-analysis [Ali et al., 2012]. The findings indicate that both individuals and their caretakers experience stigma and that it may have a negative effect on psychological well-being. Ali et al. [2012] conclude that the awareness of stigma in 
people with DID appear to be related to the extent to which individuals accept and internalize the label of intellectual disability. Longitudinal studies are needed to further explore this topic.

Overall, children with DS did not prefer the doll that was physically most similar to them. Ideas on self are likely to impact not only one's psychological well-being but also aspects of physical health, and ultimately quality of life [Sprangers and Schwartz, 1999]. This study was limited to children but it is likely that self-concept and internalized societal views are relevant for adults with DS as they face life transitions and watch their typically developing peers or siblings develop romantic relationships, start a career, and live independently. Given the potential importance of quality of life, future research is needed.

\section{Limitations of Current Study}

This was not a population-based sample and therefore our results may not be representative of the entire target population. As with any observational study there exists the possibility of a self-selection bias. We cannot exclude the possibility that there are meaningful differences between participants and non-participants that affect the generalizability of our results. Because of floor effects and lack of a normative distribution of scores on the KBIT-2 test, we treated chronological age and IQ as categorical variables. To do this, we had to establish cut points based on the means of our sample population. However, the categorical analysis was consistent with our observations of chronological age and IQ as continuous variables. Also, though this study sought to compare two dolls that appeared to be identical (except for the physical features of DS), the dolls were manufactured with different eye color. The effect of this difference is unknown.

\section{Concluding Remarks}

Self-concept is a critical indicator of an individual's quality of life or overall well-being, and by exploring the self we can begin to understand how persons with DS view themselves and their "disability". These observations are relevant to quality of life measures that may underlie clinical trial intervention, especially with the recent call for reintegrating "self" with health-related research [Sprangers and Schwartz 1999]. Additional research in this area could aid professionals in designing interventional trials with objectives targeted to the needs and desires of the participants themselves.

\section{ACKNOWLEDGMENTS}

We thank the children and their families for participating in this study. We thank the Down syndrome Association of Orange County and the Down Syndrome Association of Los Angeles for assisting us with participant recruitment. We are grateful to Ms. Sameen Sharief who assisted with data collection. We are appreciative of the Down Syndrome Program at the University of California, Irvine for providing resources in support of this project. This study was supported by grant HD-065160 (NICHD), the Alzheimer Disease Research Center (P50-AG16573), at University of California, Irvine, and the National Center for Research Resources and the National Center for Advancing Translational Sciences, National Institutes of Health (UL1 TR000153).

\section{REFERENCES}

Abraham C, Gregory N, Wolf L, Pemberton R. Self-esteem, stigma and community participation amongst people with learning difficulties living in the community. Journal of community \& applied social psychology. 2002; 12(6):430-443. 
Ali A, Hassiotis A, Strydom A, King M. Self stigma in people with intellectual disabilities and courtesy stigma in family carers: A systematic review. Research in Developmental Disabilities. 2012; 33(6):2122-2140. [PubMed: 22784823]

Ammons RB, Ammons H. Parent preferences in young children's doll-play interviews. The Journal of Abnormal and Social Psychology. 1949; 44(4):490.

Begley A. The self-perceptions of pupils with Down syndrome in relation to their academic competence, physical competence and social acceptance. International journal of Disability, Development and education. 1999; 46(4):515-529.

Begley A, Lewis A. Methodological Issues in the Assessment of the Self-concept of Children with Down Syndrome. Child and Adolescent Mental Health. 1998; 3(1):33-40.

Buckley S, Bird G, Sacks B, Archer T. A comparison of mainstream and special education for teenagers with Down syndrome: implications for parents and teachers. Downs Syndr Res Pract. 2006; 9(3):54-67. [PubMed: 16869376]

Byrd CM. The Measurement of Racial/Ethnic Identity in Children A Critical Review. Journal of Black Psychology. 2012; 38(1):3-31.

Campbell JD, Trapnell PD, Heine SJ, Katz IM, Lavallee LF, Lehman DR. Self-concept clarity: Measurement, personality correlates, and cultural boundaries. Journal of personality and social psychology. 1996; 70(1):141.

Campbell S, Braspenning J, Hutchinson A, Marshall M. Improving the quality of health care: Research methods used in developing and applying quality indicators in primary care. BMJ: British Medical Journal. 2003; 326(7393):816. [PubMed: 12689983]

Clark KB, Clark MP. Emotional factors in racial identification and preference in Negro children. The Journal of Negro Education. 1950; 19(3):341-350.

Cunningham C, Glenn S. Self-awareness in young adults with Down syndrome: I. Awareness of Down syndrome and disability. International Journal of Disability, Development and Education. 2004; 51(4):335-361.

Cuskelly M, de Jong I. Self-concept in children with Down syndrome. Down Syndrome Research and Practice. 1996; 4(2):59-64.

Dagnan D, Waring M. Linking stigma to psychological distress: testing a social-cognitive model of the experience of people with intellectual disabilities. Clinical Psychology \& Psychotherapy. 2004; 11(4):247-254.

Dunlosky, J., Bjork, RA. Handbook of metamemory and memory. CRC Press; 2008.

Forehand MR, Deshpandé R. What we see makes us who we are: Priming ethnic self-awareness and advertising response. Journal of Marketing Research. 2001:336-348.

Gallup GG. Chimpanzees: self-recognition. Science. 1970; 167(3914):86-87. [PubMed: 4982211]

Glenn S, Cunningham C. Evaluation of Self by Young People with Down Syndrome. International Journal of Disability, Development and Education. 2001; 48(2):163-177.

Gray-Little B, Hafdahl AR. Factors influencing racial comparisons of self-esteem: a quantitative review. Psychological bulletin. 2000; 126(1):26. [PubMed: 10668349]

Jacobs JH. Identity development in biracial children. 1992

Jahoda A, Markova I. Coping with social stigma: people with intellectual disabilities moving from institutions and family home. J Intellect Disabil Res. 2004; 48(Pt 8):719-729. [PubMed: 15494061]

Jones JL. Factors associated with self-concept: adolescents with intellectual and development disabilities share their perspectives. Intellectual and developmental disabilities. 2012; 50(1):31-40. [PubMed: 22316224]

Kaufman, A., Kaufman, N. Kaufman Brief Intelligence Test. Second Edition.. NCS Pearson, Inc.; 2004. p. 136

Levin H, Sears RR. Identification with parents as a determinant of doll play aggression. Child Development. 1956; 27(2):135-153. [PubMed: 13330116]

Marcu I, Oppenheim D, Koren-Karie N, Dolev S, Yirmiya N. Attachment and symbolic play in preschoolers with autism spectrum disorders. Journal of autism and developmental disorders. 2009; 39(9):1321-1328. [PubMed: 19421849] 
Markus HR, Kitayama S. Culture and the self: Implications for cognition, emotion, and motivation. Psychological review. 1991; 98(2):224.

Michalko R. The excessive appearance of disability. International Journal of Qualitative Studies in Education. 2009; 22(1):65-74.

Monteath SA, McCabe MP. The influence of societal factors on female body image. J Soc Psychol. 1997; 137(6):708-727. [PubMed: 9414624]

Newman LS, Ruble DN. Stability and change in self-understanding: The early elementary school years. Early Child Development and Care. 1988; 40(1):77-99.

Pass L, Arteche A, Cooper P, Creswell C, Murray L. Doll Play Narratives About Starting School in Children of Socially Anxious Mothers, and Their Relation to Subsequent Child School-Based Anxiety. Journal of abnormal child psychology. 2012; 40(8):1375-1384. [PubMed: 22588362]

Parker S, Mai C, Canfield M, Rickard R, Wang Y, Meyer R, Anderson P, Mason C, Collins J, Kirby R, Correa A. Updated National Birth Prevalence Estimates for Selected Birth Defects in the United States, 2004-2006. Birth Defects Res A Clin Mol Teratol. 2010; 88(12):1008-1016. [PubMed: 20878909]

Paterson L, McKenzie K, Lindsay B. Stigma, Social Comparison and Self-Esteem in Adults with an Intellectual Disability. Journal of Applied Research in Intellectual Disabilities. 2012; 25(2):166176. [PubMed: 22473968]

Petrovski P, Gleeson G. The relationship between job satisfaction and psychological health in people with an intellectual disability in competitive employment. Journal of Intellectual and Developmental Disability. 1997; 22(3):199-211.

Phillips R. Doll play as a function of the realism of the materials and the length of the experimental session. Child development. 1945; 16(3):123-143.

Presson AP, Partyka G, Jensen KM, Devine OJ, Rasmussen SA, McCabe LL, McCabe ER. Current estimate of Down Syndrome population prevalence in the United States. J Pediatr. 2013; 163(4): 1163-1168. [PubMed: 23885965]

Rafaeli-Mor E, Steinberg J. Self-Complexity and Well-Being: A Review and Research Synthesis. Personality and Social Psychology Review. 2002; 6(1):31-58.

Schalock RL. The concept of quality of life: what we know and do not know. J Intellect Disabil Res. 2004; 48(Pt 3):203-216. [PubMed: 15025663]

Sears PS. Doll play aggression in normal young children: Influence of sex, age, sibling status, father's absence. Psychological Monographs. General and Applied. 1951; 65(6):i.

Sears RR, Pintler MH, Sears PS. Effect of father separation on preschool children's doll play aggression. Child Development. 1946; 17(4):219-243. [PubMed: 20252755]

Skotko BG, Levine SP, Goldstein R. Self-perceptions from people with Down syndrome. Am J Med Genet A. 2011; 155A(10):2360-2369. [PubMed: 21910246]

Sparrow, S., Cicchetti, D., Balla, D. Vineland adaptive behavior scales: (Vineland II), survey interview form/caregiver rating form. Pearson Assessments; Livonia, MN: 2005.

Sprangers MA, Schwartz CE. Integrating response shift into health-related quality of life research: a theoretical model. Social science \& medicine. 1999; 48(11):1507-1515. [PubMed: 10400253]

Stipek D, Recchia S, McClintic S, Lewis M. Self-evaluation in young children. Monographs of the society for research in child development. 1992:i-95.

Strahan EJ, Wilson AE, Cressman KE, Buote VM. Comparing to perfection: How cultural norms for appearance affect social comparisons and self-image. Body Image. 2006; 3(3):211-227. [PubMed: 18089224]

Szivos-Bach SE. Social comparisons, stigma and mainstreaming: the self esteem of young adults with a mild mental handicap. Mental Handicap Research. 1993; 6(3):217-236.

Thiemann-Bourque KS, Brady NC, Fleming KK. Symbolic play of preschoolers with severe communication impairments with autism and other developmental delays: More similarities than differences. Journal of autism and developmental disorders. 2012; 42(5):863-873. [PubMed: 21720725]

Thompson JK, Stice E. Thin-ideal internalization: Mounting evidence for a new risk factor for bodyimage disturbance and eating pathology. Current directions in psychological science. 2001; 10(5): 181-183. 
Wohlwend KE. The boys who would be princesses: playing with gender identity intertexts in Disney Princess transmedia. Gender and Education. 2012; 24(6):593-610.

Ziller R. Self-other orientations and quality of life. Social Indicators Research. 1974; 1(3):301-327. 

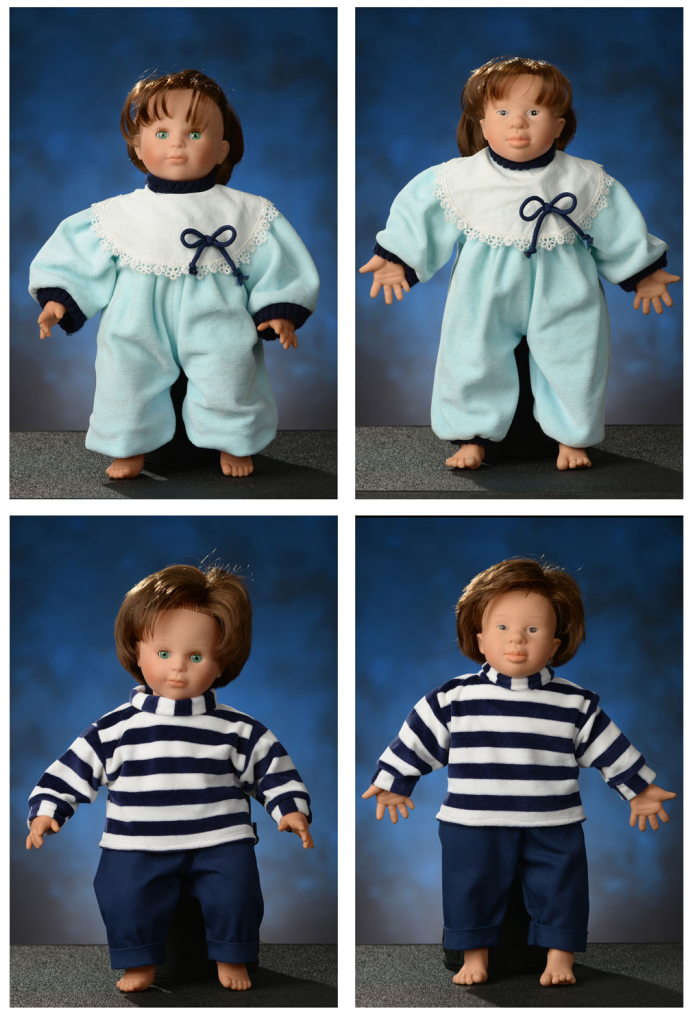

Figure 1.

Doll with "typical" features (on left) and doll with the physical features of DS (on right). The typical doll was manufactured to resemble the DS doll and only lacked recognizable characteristics of DS such as the oblique eye shape, flattened mid-face, and a flattened nasal bridge. Both males and females are shown. 

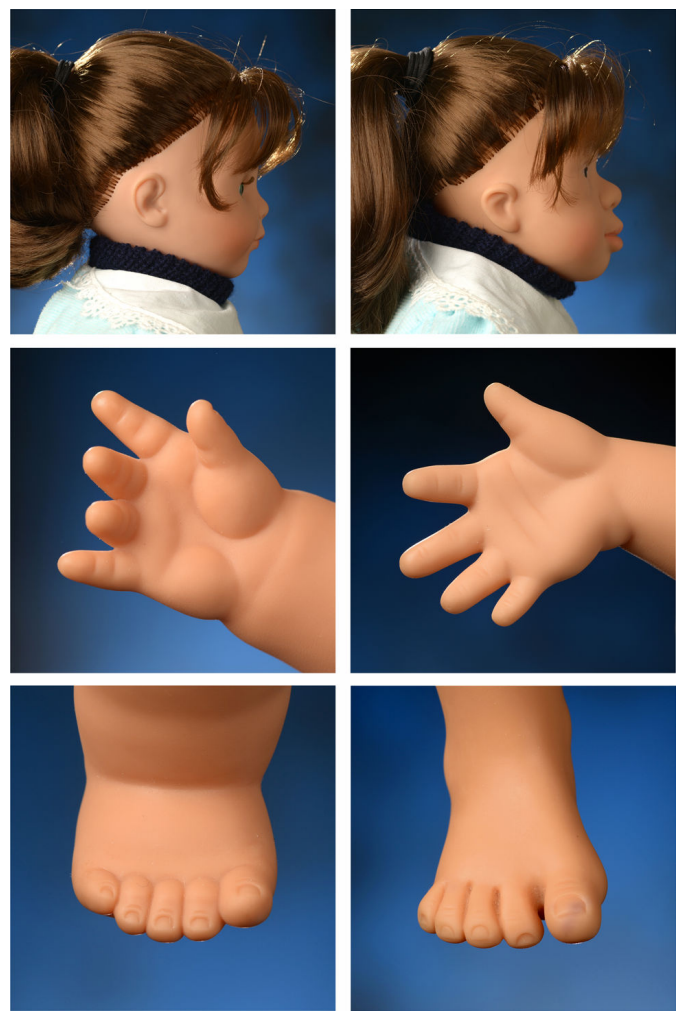

Figure 2.

a) Flattened mid-face and flattened nasal bridge, small ears slightly folded at the top, typical in DS, are apparent on the right; b) Hands reflecting differences in features. Shortened fingers are observed on the right which is characteristic of individuals with DS; c) Feet reflecting differences in features. Feet show distinctive space between the big toe and other toes (on right) in individuals with DS. 


\title{
Table I
}

\section{Questions Asked During the Interview Session}

\author{
1. Are these dolls different, if so how? \\ 2. Which doll is the prettiest doll? Why? \\ 3. Which doll is the smartest doll? Why? \\ 4. Which doll has most friends? Why? \\ 5. Which doll is best at sports? Why? \\ 6. Which doll is the good person? Why? \\ 7. Which doll do you like the most? Why? \\ 8. Which doll looks like you? Why?
}


Table II

Demographic Characteristics of Study Population (N=54)

\begin{tabular}{|c|c|c|c|c|}
\hline Variables & & & Frequency & $\%$ \\
\hline \multicolumn{5}{|l|}{ Gender } \\
\hline Male & & & 26 & 48 \\
\hline Female & & & 28 & 52 \\
\hline \multicolumn{5}{|l|}{ Race/Ethnicity } \\
\hline Caucasian/non-Hispanic & & & 30 & 56 \\
\hline Hispanic & & & 18 & 33 \\
\hline Asian & & & 4 & 7 \\
\hline African-American & & & 1 & 2 \\
\hline Other & & & 1 & 2 \\
\hline \multicolumn{5}{|l|}{ Aware he or she has DS } \\
\hline Yes & & & 16 & 30 \\
\hline No & & & 38 & 70 \\
\hline \multicolumn{5}{|c|}{ Exposed to children with DS in last 6 months } \\
\hline Yes & & & 50 & 93 \\
\hline No & & & 4 & 7 \\
\hline Variables & Mean & SD & Range & \\
\hline Chronological Age & 10.1 & 3.7 & $4.0-17.9$ & \\
\hline IQ Score & 51.6 & 10.4 & $40-75$ & \\
\hline Vineland Composite Score & 71.5 & 7.3 & 56-89 & \\
\hline
\end{tabular}


Table III

Participant Preferences, Overall Attributions, and Selections

\begin{tabular}{|c|c|c|c|c|c|c|c|}
\hline & & \multicolumn{2}{|c|}{ TD Doll } & \multicolumn{2}{|c|}{ DS Doll } & \multicolumn{2}{|c|}{ Statistical Values } \\
\hline & & $\mathbf{N}$ & $\%$ & $\mathbf{N}$ & $\%$ & p-value & $95 \%$ CI (TD choice) ${ }^{c}$ \\
\hline Doll Preference & All & 37 & 71 & 15 & 29 & $0.003^{a}$ & $57 \%-83 \%$ \\
\hline \multirow[t]{2}{*}{ Gender } & Male & 18 & 72 & 7 & 28 & $1.00^{b}$ & \\
\hline & Female & 19 & 70 & 8 & 30 & & \\
\hline \multirow[t]{2}{*}{ Awareness of DS } & Aware & 12 & 80 & 3 & 20 & $0.51^{b}$ & \\
\hline & Not Aware & 25 & 68 & 12 & 32 & & \\
\hline \multirow[t]{2}{*}{ Chronological Age } & Older (Age >10) & 17 & 81 & 4 & 19 & $0.23^{b}$ & \\
\hline & Younger (Age <10) & 20 & 65 & 11 & 35 & & \\
\hline \multirow[t]{2}{*}{ IQ (KBIT-2) } & Higher (IQ > 52) & 18 & 75 & 6 & 25 & $0.76^{b}$ & \\
\hline & Lower (IQ <52) & 19 & 68 & 9 & 32 & & \\
\hline Overall Positive Attributions & All & 43 & 83 & 9 & 17 & $<0.001^{a}$ & $70 \%-92 \%$ \\
\hline \multirow[t]{2}{*}{ Gender } & Male & 20 & 80 & 5 & 20 & $0.72^{b}$ & \\
\hline & Female & 23 & 85 & 4 & 15 & & \\
\hline \multirow[t]{2}{*}{ Awareness of DS } & Aware & 13 & 81 & 3 & 19 & $1.00^{b}$ & \\
\hline & Not Aware & 30 & 83 & 6 & 17 & & \\
\hline \multirow[t]{2}{*}{ Chronological Age } & Older (Age >10) & 17 & 77 & 5 & 23 & $0.47^{b}$ & \\
\hline & Younger (Age <10) & 26 & 87 & 4 & 13 & & \\
\hline \multirow[t]{2}{*}{ IQ (KBIT-2) } & Higher (IQ > 52) & 21 & 84 & 5 & 16 & $1.00^{b}$ & \\
\hline & Lower (IQ <52) & 22 & 81 & 5 & 19 & & \\
\hline \multicolumn{8}{|l|}{ Positive Attributions } \\
\hline Prettiest & All & 43 & 83 & 9 & 17 & $<0.001^{a}$ & $70 \%-92 \%$ \\
\hline Smartest & All & 27 & 52 & 25 & 48 & $0.89^{a}$ & $38 \%-66 \%$ \\
\hline Has most friends & All & 38 & 72 & 15 & 28 & $0.002^{a}$ & $58 \%-83 \%$ \\
\hline Best at sports & All & 37 & 71 & 15 & 29 & $0.003^{a}$ & $57 \%-83 \%$ \\
\hline Is the good person & All & 36 & 69 & 16 & 31 & $0.008^{a}$ & $55 \%-81 \%$ \\
\hline
\end{tabular}

TD: typically developing; DS: Down syndrome; CI: Confidence interval; IQ: Intelligence quotient; KBIT-2: Kaufman Brief Intelligence Test, Second Edition

${ }^{b}$ Fisher's Exact test for difference in preference by gender or awareness

${ }^{a}$ Binomial test of null hypothesis that $\mathrm{p}=50 \%$

${ }^{c}$ Clopper-Pearson $95 \%$ binomial confidence interval 
Table IV

Self-image and Resemblance

\begin{tabular}{|c|c|c|c|c|c|c|}
\hline & & \multicolumn{2}{|c|}{ Resembles TD Doll } & \multicolumn{2}{|c|}{ Resembles DS Doll } & \multirow[b]{2}{*}{ p-value } \\
\hline & & $\mathbf{N}$ & $\%$ & $\mathbf{N}$ & $\%$ & \\
\hline \multirow[t]{2}{*}{ Doll Preference } & Prefers TD Doll & 24 & 67 & 12 & 33 & $0.198^{b}$ \\
\hline & Prefers DS Doll & 6 & 43 & 8 & 57 & \\
\hline \multirow[t]{2}{*}{ Overall Positive Attributions } & TD Doll & 29 & 67 & 14 & 33 & $0.003^{b}$ \\
\hline & DS Doll & 1 & 11 & 8 & 89 & \\
\hline \multirow[t]{2}{*}{ Are dolls different? } & Yes & 21 & 60 & 14 & 40 & $0.54^{b}$ \\
\hline & No & 7 & 47 & 8 & 53 & \\
\hline \multirow[t]{2}{*}{ Recognizes self in mirror? } & Yes & 27 & 59 & 19 & 41 & $0.69^{b}$ \\
\hline & No & 3 & 50 & 3 & 50 & \\
\hline Total & & 30 & 58 & 22 & 42 & $0.33^{a}$ \\
\hline
\end{tabular}

TD: typically developing; DS: Down syndrome

${ }^{a}$ Binomial test of null hypothesis that $\mathrm{p}=50 \%$

${ }^{b}$ Fisher's Exact test for difference in preference by gender or awareness 